\title{
Benefits of Elective Laparoscopic 2-Stage Restorative Proctocolectomy for Ulcerative Colitis in Korea
}

\author{
Sun Min Park, Won-Kyung Kang \\ Department of Surgery, College of Medicine, The Catholic University of Korea, Seoul, Korea
}

\section{See Articles on Page 41-47}

Ulcerative colitis (UC) is a nonspecific inflammatory enteropathy characterized by bloody diarrhea accompanied by urgency and tenesmus. Approximately $15 \%$ of patients suffering UC develop acute attacks of severe colitis, and approximately $30 \%$ of these patients need colectomy [1]. Further, approximately $10 \%$ of patients first diagnosed with UC also need surgery [2]. Indications suggesting surgery for UC are as follows: (1) the major complication of acute severe ulcerative colitis (i.e., toxic megacolon, perforation, severe colorectal bleeding, multiple organ dysfunction syndrome); (2) refractory UC which includes both steroid dependency and immunomodulators, or biologic-refractory UC; (3) associated dysplasia and carcinoma [3].

Surgical approaches for UC vary widely from the open subtotal colectomy with end ileostomy to a laparoscopic restorative proctocolectomy (RPC) according to the severity of disease. For the cases of elective surgery indicated for refractory UC or for UC patients with dysplasia who have favorable general conditions, the employment of laparoscopic surgery can be considered. However, for cases of severe UC and emergency surgery, the feasibility of employment of the laparoscopic approach remains controversial [4].

Studies have compared the open- and laparoscopic surgical approaches for UC. Larson et al. [5] compared surgical groups that used laparoscopic restorative proctocolectomy (RPC) and open RPC among patients suffering from chronic UC and FAP. The

Correspondence to: Won-Kyung Kang, M.D.

Department of Surgery, Yeouido St. Mary's Hospital, College of Medicine, The Catholic University of Korea, 1063 (yuksam)-ro, Yeongdeungpo-gu, Seoul 07345, Korea

Tel: +82-2-3779-1033, Fax: +82-2-780-9114

E-mail: wonkkang@catholic.ac.kr

ORCID: https://orcid.org/0000-0002-3337-0644

(c) 2020 The Korean Society of Coloproctology

This is an open-access article distributed under the terms of the Creative Commons Attribution NonCommercial License (https://creativecommons.org/licenses/by-nc/4.0) which permits unrestricted noncommercial use, distribution, and reproduction in any medium, provided the original work is properly cited. laparoscopic group had a postoperative morbidity of $6 \%$ and the open group had $12 \%$, which were not statistically different $(\mathrm{P}=$ 0.39 ). There were also no significant differences in terms of quality of life $(\mathrm{P}=0.95)$. In a study conducted by Chung et al. [6], surgeons utilized laparoscopic- and open surgeries as the initial operation among the 3-stage RPC procedures for severe UC. When surgery types were compared to each other, the postoperative morbidity for the laparoscopic approach appeared significantly lower than open surgery ( $24 \%$ and $53 \%$, respectively; $\mathrm{P}=0.0386$ ) together with a significantly shorter time of bowel function recovery ( 2.6 days and 5.5 days, respectively; $\mathrm{P}=0.0001$ ). In some studies, laparoscopic surgery appeared to require more time than open surgery [7-9].

Bong et al.[10] compared the short-term outcomes of the open and laparoscopic approaches to 2-stage RPC for patients suffering from refractory UC and UC with dysplasia. The patients in the laparoscopic surgery group had lower mean body mass index $(\mathrm{P}$ $=0.025)$, shorter bowel function recovery time $(\mathrm{P}=0.004)$, and less postoperative day (POD) 1 and $\mathrm{POD} 7$ pain $(\mathrm{P}=0.029$ and $\mathrm{P}$ $=0.027$, respectively), than those in the open surgery group. In terms of postoperative complications, there were no significant differences between groups. However, in regard to the appearance of ileus, the laparoscopic surgery patient group had significantly fewer cases of ileus than the open surgery group (7.7\% vs. $27.7 \%$, $\mathrm{P}=0.043)$.

In summary, laparoscopic RPC seems comparable to open RPC for UC; and in cases of severe UC outside the emergency setting, the selection of the laparoscopic approach as an alternative to open surgery seems feasible. Further, when laparoscopic surgery is used initially, but surgery time extends too long due to patient deteriorating condition or severe accretion due to inflammation, the selection of open conversion is another alternative that can be considered. Thus, laparoscopic RPC for selected UC cases can make use of the advantages of general laparoscopic approaches as a favorable treatment option. Currently, several hospitals are trying to take laparoscopic approaches for UC in Korea, but the consequences thereof are yet to be reported; the results presented in this study can be regarded as one such significant report. 


\section{CONFLICT OF INTEREST}

No potential conflict of interest relevant to this article was reported.

\section{REFERENCES}

1. Carter MJ, Lobo AJ, Travis SP; IBD Section, British Society of Gastroenterology. Guidelines for the management of inflammatory bowel disease in adults. Gut 2004;53 Suppl 5:V1-16.

2. Leijonmarck CE, Persson PG, Hellers G. Factors affecting colectomy rate in ulcerative colitis: an epidemiologic study. Gut 1990; 31:329-33.

3. Gallo G, Kotze PG, Spinelli A. Surgery in ulcerative colitis: When? How? Best Pract Res Clin Gastroenterol 2018;32-33:71-8.

4. Kawamura J, Hasegawa S, Kawada K, Yamaguchi T, Nagayama S, Matsusue R, et al. Feasibility and safety of laparoscopic total proctocolectomy with ileal pouch-anal anastomosis for severe ulcerative colitis. Asian J Endosc Surg 2013;6:271-8.

5. Larson DW, Dozois EJ, Piotrowicz K, Cima RR, Wolff BG, YoungFadok TM. Laparoscopic-assisted vs. open ileal pouch-anal anastomosis: functional outcome in a case-matched series. Dis Colon
Rectum 2005;48:1845-50.

6. Chung TP, Fleshman JW, Birnbaum EH, Hunt SR, Dietz DW, Read TE, et al. Laparoscopic vs. open total abdominal colectomy for severe colitis: impact on recovery and subsequent completion restorative proctectomy. Dis Colon Rectum 2009;52:4-10.

7. Gorgun E, Cengiz TB, Aytac E, Aiello A, da Silva G, Goldberg JM, et al. Does laparoscopic ileal pouch-anal anastomosis reduce infertility compared with open approach? Surgery 2019;166:670-7.

8. Mineccia M, Cravero F, Massucco P, Portigliotti L, Bertolino F, Daperno $\mathrm{M}$, et al. Laparoscopic vs open restorative proctocolectomy with IPAA for ulcerative colitis: Impact of surgical technique on creating a well functioning pouch. Int J Surg 2018;55: 201-6.

9. Ryoo SB, Oh HK, Han EC, Ha HK, Moon SH, Choe EK, et al. Complications after ileal pouch-anal anastomosis in Korean patients with ulcerative colitis. World J Gastroenterol 2014;20:748896.

10. Bong JW, Yoon YS, Lee JL, Kim CW, Park IJ, Lim SB, et al. Shortterm outcomes of elective 2-stage restorative proctocolectomy for ulcerative colitis in Korea: does laparoscopy have benefits? Ann Coloproctol 2020;36:41-7. 